\title{
Janelas indiscretas e ruas devassadas: duas matrizes para a representação da cidade / Indiscreet windows and devastated streets: two matrices for the representation of the city ${ }^{1}$ \\ Renato Cordeiro Gomes ${ }^{2}$
}

\section{Resumo:}

A representação da cidade moderna foi fixada, no século XIX, por duas imagens - a janela e a rua - que acabaram se tornando duas matrizes construídas, respectivamente, pelos contos " A janela de esquina do meu primo" (1822), de A.T. Hoffmann (pela primeira vez traduzido no Brasil, em 2010, e que motivou este trabalho) e "O homem da multidão" (1840), de Edgar Allan Poe. Propõe-se, de um ponto de vista contemporâneo, estudar essas matrizes, que associam visibilidade, abertura e espaço público, e que são, numa tradição, reconfiguradas em produtos midiáticos e literários, funcionando como estratégias discursivas, justamente, para fixar a cidade que se transforma incessantemente. Indaga-se se tais matrizes são garantia de significação e o que resta delas, hoje, frente à expansão da Internet, dos computadores pessoas e das redes sociais

Palavras-chave: Representação da cidade; janela; rua; Hoffmann; Poe; flâneur e visibilidade; Expansão da Internet

\begin{abstract}
The representation of the modern city was established in the nineteenth century by two images: the window and the street. They turned out to be two matrices built, respectively, by the tales "My Cousin's Corner Window" (1822) by A.T. Hoffmann (first translated in Brazil in 2010 and the motivation of this work) and "The Man of the Crowd" (1840) by Edgar Allan Poe. It is proposed, from a contemporary point of view, to study these matrices which associate visibility, openness and public space, and that are, in a tradition, reconfigured in literary and media products, working as discursive strategies, precisely, to settle the city that keeps on transforming relentlessly. It is questioned if such matrices are a guarantee of meaning and what remains of them,
\end{abstract}

\footnotetext{
${ }^{1}$ Trabalho originalmente apresentado ao Grupo de Trabalho Cultura das Mídias do XX Encontro da Compós, na Universidade Federal do Rio Grande do Sul, Porto Alegre, de 14 a 17 de junho de 2011.

2 Pontifícia Universidade Católica do Rio de Janeiro (PUC-Rio), doutor, professor associado, rcgomes@domain.com.br.
} 
today, given the expansion of the Internet, the personal computers and the social networks.

Keywords: City representation; window; street; Hoffmann; Poe; flâneur and visibility; Internet expansion.

"Antigamente, vivíamos em países e cidades. Hoje vivemos na Internet". Esta frase num diálogo do filme $A$ rede social (The Social Network, EUA, 2010), de David Fincher, fornece um bom índice para mostrar como a criação e a expansão do Facebook vai cobrindo o mundo e substituindo a rua e a janela da cidade real, por um fluxo que circula por uma cibercidade. A rua transforma-se em infovias; as janelas, em Windows, esse Gestor de Interface, criado pela Microsoft a partir de setembro de 1981, cuja versão Windows NT foi lançada em agosto de 1993. É o

sistema operacional mais utilizado em computadores pessoais no mundo. Interessa, aqui, reter esses lugares-comuns, para sublinhar o caráter metafórico dessa nomeação cujo registro trouxe complicações para a Microsft, justamente por tratar-se de uma palavra (windows) de uso corrente em inglês, a língua geral da atualidade. O que, entretanto, a metáfora sugere são os traços semânticos de abertura para o exterior, que permite a iluminação e a ventilação (Cf. a etimologia da palavra em inglês) e facilita a visibilidade da paisagem exterior. Aí se embute a noção de espaço. Espaço exterior - visibilidade - abertura são os mesmos traços pertinentes (ou semas) da imagem da janela pela qual se vê o mundo, a cidade; mediação que funciona como um dispositivo para se representar a cidade moderna.

Esta associação foi motivada pela bela edição do conto A janela de esquina do meu primo, de E.T.A. Hoffmann (1776-1822), pela CosacNaify, em 2010. Um precioso livro, com a eficiente tradução de Maria Aparecida Barbosa, enriquecida de notas informativas, bem como as ilustrações de Daniel Bueno (que capta a fragmentação moderníssima que o texto oferece, numa antecipação a essa editoriais que funcionam como suplementos à narrativa alemã, publicada postumamente em 1822, e até agora sem tradução no Brasil. Somado a $O$ homem 
da multidão (1840), de Poe, fixam ambos duas matizes centradas nas imagens - da janela e da rua, que se tornam recorrentes nas artes, na literatura e nas mídias, para representação da vida urbana. 0 americano retoma, alguns anos depois, certos tópicos que o alemão inaugurara; ambos tematizam a legibilidade da cidade moderna, fixam a visão atomizada da multidão, na mesma época comentada pelo jovem Engels ( $A$ situação da classe trabalhadora na Inglaterra), contribuindo, por sua vez, para semantizar o espaço público que emergiu como símbolo fundamental da vida moderna, imagem que se cristalizou como celebração da vitalidade urbana, de sua diversidade e plenitude, como demonstrou Marshall Berman em Tudo que é sólido desmancha no ar (1986). Matrizes que tiveram fundamental papel na invenção da cultura moderna das cidades, contribuindo para a construção do imaginário urbano - seu museu imaginário - ou, dito de outro modo, o próprio imaginário da modernidade, como afirma Jean Dethier, ao retomar essa expressão de André Malraux (1994, p. 16).

Se a imagem da rua que emblematiza a cidade moderna foi fixada por Poe, a cidade vista através de um janela remete ao conto "A janela de esquina do meu primo". Essa dupla imagética que forma um pendant, já foi apontada por Benjamin em seus textos sobre Baudelaire, ou em duas pequenas citações do Livro das passagens, e também por Jean Starobinski. Diz este professor da Universidade de Genebra, no ensaio: "Fenêtres - de Rouseau à Baudelaire":

Os belos estudos de Walter Benjamin contribuíram para ligar muito estreitamente à imagem da cidade do século XIX - Paris - o movimento da flânerie, movimento sem finalidade prática, aberto ao encontro, ao inesperado, à súbita aparição de monstros e maravilhas. Esta observação é perspicaz, mas é preciso evitar isolá-la. Ao prestar-se uma atenção privilegiada à flânerie, esquece-se que o passeio solitário através das ruas e dos bairros não é senão um dos aspectos da relação do indivíduo moderno com a cidade. A flânerie ganha toda sua importância se se observa que ela entra em relação contrastante com uma outra atitude, não menos reveladora, não menos rica de significações: a imobilidade contemplativa, a cidade olhada apaixonadamente por um recluso voluntário, do alto de uma janela. Trata-se de dois pontos de vista sobre a cidade, um movente, levado pelo fluxo da rua, o outro, fixo, desdobrando o olhar sobre os diversos acidentes da paisagem urbana. (STAROBINSKI, 1984, p. 181). 
O conto de Hoffmann ("Des Vetters Eckfenster"), escrito no começo de abril de 1822, recicla uma narrativa humorística de K. F. Kretschmann, publicada em 1798, no Almanach para 1799, com o objetivo de divertimento em família, intitulado Scarron em sua janela, em que um escritor paralisado observa de sua casa os passantes e traça-lhes retratos humorísticos. Hoffmann gravemente doente reconhece-se nessa situação e compõe um auto-retrato literário sob a forma de um diálogo no qual passa em revista suas idéias sobre a arte e o artista. 0 texto foi publicado no Spectateur, algumas semanas antes da morte de Hoffmann.

Retomando a mesma imagem e situação da narrativa de Kretschmann, o escritor é definido no conto de Hoffmann como um solitário na janela em face da cidade. De trás de sua janela de esquina, que se abre para um mercado, o escritor, ao contrário do flâneur, é uma consciência separada: ele vê tudo e não participa, impedido que está de locomover-se, pois, depois de uma longa doença, perdera o movimento das pernas. Por esta característica, introduz-se o tema da paralisia, que redunda, no entrecho da narrativa, em adotar-se um ponto de vista fixo, que vai ser coadjuvado pela situação dialogal que discursivamente estrutura o conto. A situação assim é formada pelo diálogo entre um Eu que narra e o primo escritor, cuja "morada está localizada na região mais bonita da capital ou seja, em frente à praça do mercado, rodeada por construções suntuosas, em cujo centro se ergue o colossal edifício do teatro, genialmente concebido. É um prédio de esquina o que meu primo habita, e da janela de um pequeno gabinete ele abarca num lance de olhos todo o panorama da grandiosa praça" (HOFFMANN, 2010, p. 11) (palavras do eu que narra e participa do diálogo, e que por sua vez não é capaz de escrever, de pôr a imaginação para funcionar na criação ficcional). Na cadeira de rodas, o primo tem a janela como consolo (como afirma ao narrador) e completa: "Daí eu encontro a vida, com seu reluzir, sua mudança de cores, e me sinto cheio de interesse por sua incessante agitação" (p. 13). Ao observar com tal interesse a praça do mercado, o primo vê o mundo lá fora como um espetáculo, teatro do cotidiano cujo enredo vai se compondo como um mosaico. Se a praça é o palco com seus atores, o gabinete é semelhante a um camarote, ponto de observação de onde o binóculo com que olha, recorta e aproxima as cenas. A sensibilidade aguçada do primo levao a ensinar ao narrador a arte de ver. Esse eu passa então a ensaiar a descrição das 
cenas, embora a interpretação que se dá através de micro-narrativas caiba ao primo, senhor da fabulação, que ensina a estabelecer o jogo das aparências, como índices que revelam sentidos escondidos.

Como mestre da arte de ver, associando visibilidade - janela - abertura para o exterior, o primo diz ao narrador:

Falta-lhe a disposição mais elementar para poder seguir os passos de seu primo digno e paralítico, ou seja, um olho! Um olho que realmente enxergue! (...) Fixar o olhar propicia o enxergar nítido. (...) Este mercado não te oferece senão o espetáculo de um mosaico alucinante, de uma multidão agitada sem razão. Oh! meu amigo, o mercado figura para ti muito diferente que para mim! Eu aí vejo desenrolar, como num palco de teatro, os múltiplos episódios da vida burguesa e meu espírito (...) constrói esboço sobre esboço, com traço bastante ousado. Vamos, primo! gostaria de experimentar levar-te ao menos a adquirir este a b c da arte! Assim, olha lá na rua, exatamente diante de mim; toma este binóculo; vê essa pessoa tão singularmente vestida, que leva no braço um grande cesto? (HOFFMANN, 2010, p. 17-19)

Desta maneira, o primo ensina ao narrador a fixar um ponto de vista para aprender a ver corretamente; ensina-lhe a "arte de enxergar", chamando a atenção para os detalhes engraçados que se oferecem a seus olhares. E vai transmitindo as instruções de "como ver/ler", treina-o a ler sobre as fisionomias, que o primo interpreta, deduzindo a "crônica escandalosa", os dramas. Com suas hipóteses narrativas, produtos de seu talento de escritor, o primo ordena a confusão da multidão, complementando as descrições que o narrador vai exercitando. 0 discurso dos dois personagens em diálogo articula os modos de representação do espaço e do tempo, concretizando no discurso "um verdadeiro orbis pictus" (como diz o primo em relação a um bric-à-brac do mercado), ou seja, um mundo de imagens, sugerido pelo título de um conjunto de textos do pedagogo Comenius (1592-1670), frequentemente retomado para designar este gênero de enciclopédia [a praça com o mercado seria uma miniatura dessa enciclopédia urbana semelhante ao que Jonhathan Rabin fala em Soft city, ensaio de 1988, que propõe, a partir dos movimentos urbanos dos rebeldes anos 60, uma visão da cidade para além das divisões de classe e dos aspectos funcionalistas e racionais]. Procedendo 
então a um inventário espacial, em que "o visível é um ponto de apoio para o olho" (como afirma o narrador), o primo mergulha o olhar na descrição do mercado que tem sob sua janela, constituindo o elemento que lhe permite a identificação com um mundo vivo. Ainda que veja apenas o que a janela permite e o binóculo (outra janela em miniatura) recorta, ele tem sob seus olhos o espetáculo do possível do qual ele está excluído, mas que se impõe com um relevante suplemento. Conjuga observação e reflexão. A acuidade visual, a exatidão da descrição, a multiplicação dos detalhes são sempre saída para esta consciência super-aguçada. A observação final do primo bem expressa esta consciência, ao estabelecer o contraste entre sua imobilidade contemplativa (a paralisia) e a vida que muda sem cessar (a que se pode relacionar à modernidade captada pelas alegorias urbanas poetizadas por Baudelaire). Conclui o primo:

Este mercado é, neste momento ainda, uma imagem fiel da vida cambiante que não cessa. Uma febril atividade e as necessidades do momento reuniram esta multidão; alguns instantes foram suficientes para que tudo seja de novo deserto; as vozes que experimentavam dominar o tumulto foram agora extintas, e cada lugar abandonado não exprime senão mais vivamente um aceno: passou!. (HOFFMANN, 2010, p. 56-57)

O espetáculo fugaz, preso ao contingente, ao efêmero, que tenta fixar o instante que flui, traço paradoxal da modernidade, que busca fixar o que não pode ser fixado, como Leo Charney atesta, relacionando ao cinema (2004), permite ao narrador deduzir uma dupla pedagogia. Ao explicar modos de ler a cidade moderna não pela flânerie fixada pela imagem de um homem caminhando solitário pela rua (cf.: "O homem da multidão"), mas pela imobilidade que leva ao aguçamento do olhar que aprende a ver a cena urbana enquadrada pela janela, o narrador tentar explicar o prazer que essa janela proporcionava ao primo e do qual ambos, o narrador e o primo, tiram o preceito moral possibilitado por essa pedagogia que retoma as palavras de Horácio: "Et si male nunc, non olim sic erit", e se as coisas vão mal, um dia não será mais assim. [Talvez não seja de todo inútil lembrar um dado biográfico: Hoffmann escreveu este conto dias antes de morrer]. A afirmativa de Horácio aparece, não à toa, duas vezes no texto, na voz do eunarrador, como premissa (no início) e no fim, funcionando também como moldura 
de uma janela, que é o texto. Do preceito moral a frase passa também a preceito estético, que se relaciona à captação do efêmero, do que passa (cidade: aquela que passa - Baudelaire: “A une passante"), que se remete à mudança, a anunciar aquilo que não é, mas está a ponto de ser, que aponta para o futuro. Atado a este preceito, o primo escritor é adepto do artifício, sua maneira de representar o mundo: embora não ande (não tem o solvitur ambulando - do conto "A arte de andar nas ruas do Rio de Janeiro", de Rubem Fonseca, ou como o flâneur), ele vê e escreve.

A matriz situacional e imagética desse conto de Hoffmann é nitidamente retomada e desdobrada, alguns anos depois, por Poe, em seu famoso conto "O homem da multidão", de 1840, que situa o primeiro movimento de sua narrativa da janela de um café no centro de Londres, de onde observa a multidão que passa. Ao recortar desse conjunto a figura de um velho, "o gênio do crime", abandona a posição estática, semelhante à de Hoffmann, e aventura-se a abrir caminho da multidão (já sugerida na observação do primo que olha a praça do mercado), para perseguir e decifrar a estranha personagem. A deambulação pela rua permite a construir a figura do flâneur, que em seu deslocamento fornece os traços para fixar a outra matriz relativa à representação da cidade moderna, por sua vez associada à questão do ver, de andar pelo espaço público e da legibilidade da cidade, enigma a ser decifrado.

O tópico da ilegibilidade, anunciado na abertura do texto ("De certo livro alemão, disse-se, com propriedade, que es lässt sich nicht lesen - não se deixa ler. Há certos segredos que não consentem ser ditos"), será relacionado com o espetáculo da rua londrina que o narrador observa e tenta ler. Associando livros, homens, rua e cidade numa analogia que se projeta em mistérios não revelados, indecifráveis, Poe aponta para um regime de profundidade, pois há um sentido a se anunciar, sentido que precisa ser "descoberto", pela remoção das camadas que o envolvem. A esta concepção Poe associa o segredo de uma intimidade e o espaço público, a rua que funciona como um palco que oferece um espetáculo (de spetaculum, a festa pública) ao espectador, aquele que, colocando-se em um determinado lugar, vê o espetáculo e é capaz de voltar-se para o speculandus - 
com a acepção de especular, investigar, examinar, vigiar, observar (observe-se a recorrência desses e de outros verbos do mesmo campo semântico no conto de Poe) [ver CHAUÍ,1988, p. 36). Assim, o espectador é aquele que busca esclarecer o obscuro ou o reprimido que afinal se revela. 0 entrecho da narrativa demonstra que havia espetáculo, havia cena e, portanto, promessa de significação que desafiava aquele a quem cabia decifrar, ler, e para tal teria de guardar certa distância, e não a completa imersão no objeto e a conseqüente anulação de qualquer diferença do sujeito (ver ARANTES, 1988, p. 269).

A afirmação inicial do conto tem caráter geral e apresenta a tese, que permite desencadear o entrecho que terá a rua como palco e seu cenário e como laboratório. Glosando palavras do texto, poderíamos produzir fragmentos narrativos. Em Londres, o narrador, um homem que, depois de longa doença, calmo, mas inquisitivo, depois de superado o ennui, com o "intelecto eletrificado", interessa-se por tudo e aventura-se no burburinho da rua da cidade grande. A convalescença leva-o para a rua, para o centro da cidade fervilhante, para o contato com a multidão. Ressurgido para a vida e desligado das correspondências naturais (em relação à natureza), deixa-se seduzir pelo turbilhão da metrópole que o leva à experimentação, ao ensaio, de ler, de decifrar o mistério do artificial de cena urbana.

Instala-se, num primeiro momento, atrás da janela de um café e examina os fregueses à sua volta, os anúncios de jornal, mas, acima de tudo, seu olhar se dirige à multidão que passa aos encontrões (a imagem do choque) diante de sua janela, a moldura que enquadra as cenas móveis da rua que são recortadas de uma totalidade inapreensível devido ao ponto de vista do observador. A janela, limite entre um dentro e um fora, faz o café funcionar como um camarote de teatro [o quarto do primo do conto de Hoffmann já anunciava essa imagem], indicando um lugar de não permanência (um não-lugar, na acepção de Marc Augé, lugar não identitário), de onde o observador se deixa dominar pela "emoção inédita", provocada pelas "ondas de passantes" e absorve-se na contemplação da cena exterior da multidão que passa no palco da rua. Quando a noite avança, progride o interesse pela cena, e a iluminação artificial leva-o ao exame das faces individuais e 
dos grupos de passantes que desfilam com rapidez diante de sua janela. Observa, especula, examina, analisa, agrupa, classifica, hierarquiza, ordena o que contempla do espetáculo da rua. Os tipos humanos são, assim, classificados pelos aspectos exteriores que se dão a ver (roupas, gestos, fisionomia ... máscaras, enfim, que escondem significações, cujos pequenos índices percebidos permitem, apenas com uma olhadela, "ler a história de longos anos"). Nesta tarefa, revela conhecimento preciso dos elementos que compõem o movimento repetitivo das marés - "o mar tumultuoso de cabeças humanas". "Procura levar a cabo as novas experiências da cidade dentro da moldura das velhas transmitidas pela natureza" - afirma Walter Benjamin (1989, p. 226). Daí a metáfora do mar, das ondas, cunhada na analogia com as forças da natureza, com a qual o narrador nomeia a multidão que ele tenta ler pela forma exterior que o olhar registra. 0 investimento nessa leitura encaminha-se para a uniformidade dos grupos que são classificados e, por oposição, marcam as diferenças (que também permitem classificar): uniformidade da indumentária, do comportamento, dos gestos. Segundo Benjamin, “o texto de Poe torna inteligível a verdadeira relação entre selvageria e disciplina. Seus transeuntes se comportam como se adaptados à automatização, só conseguissem se expressar de forma automática. Seu comportamento é uma reação a choques" (1986, p. 126): "Muitos dos passantes tinham um aspecto prazerosamente comercial e pareciam pensar apenas em abrir caminho através da turba" sustenta o narrador. E acrescenta Benjamin:

Em Poe, as pessoas se comportam como se só pudessem se exprimir reflexamente. Essa movimentação tem um efeito ainda mais desumano porque se fala apenas de seres humanos. Quando a multidão se congestiona, não é porque o trânsito de veículos a detenha - em parte alguma se menciona o trânsito - mas sim porque é bloqueada por outra multidão". (1998, p. 50).

Num segundo momento, ocupado em examinar a turba, depara-se com o "semblante de absoluta indiossincrasia da expressão" de um velho decrépito que desperta a curiosidade de "analisar o significado que este homem sugerira". Abandonando a posição de observador analítico da multidão, vai misturar-se a ela na perseguição "inútil". De um ponto de vista fixo, desloca-se para a mobilidade do labirinto das ruas na perseguição desse homem, abrindo caminho na multidão. 
Atraído pela singularidade do estranho, tenta atingir o conhecimento da individualidade desse homem para além da classificação pautada na uniformidade. Pensa a princípio ser fácil decifrar com apenas uma olhadela "a história que ele traz escrita no peito". Ao perseguir o velho que vagueia sem objetivo aparente, não compreende o sentido de seus percursos, a inconstância de suas ações e a indiferença desse estranho que jamais se dá conta do perseguidor. Não consegue afinal desvendar "o incógnito do ser humano", uma "verdade" tida como um precedente críptico que o narrador tenta inutilmente decifrar.

Com sua tendência racionalizante, especulativa, dedutiva, o narrador comporta como uma espécie de detetive que procura decifrar um enigma pela recolha de índices que o percurso (interpretativo, de leitura) dá a ver, a fim de demonstrar uma verdade escondida que afinal seria revelada, mas no conto de Poe essa operação de uma espécie de "máquina de raciocinar", de estabelecer sentidos, é deceptiva, mas remete para um outro aspecto observado por Benjamin (1986, p. 41-44), qual seja, a supressão dos vestígios do indivíduo na multidão, ou melhor, o desaparecimento de vestígios da vida privada na cidade grande que acompanha o desaparecimento do ser humano na massa. O narrador, portanto, não consegue desvelar o precedente críptico do personagem, sua técnica de investigação não leva a proceder a uma reconstituição desse precedente, a história que esse "gênio do crime" supostamente trazia escrita no peito. Apenas lê a superfície que o olhar registra; aponta aqui para um outro regime de significação: aquele que nada esconde, pois se revela na superfície.

Apesar de sugerir esse outro regime, o conto de Poe não deixa de confirmar em seu fecho o tópico da ilegibilidade, isto é, fica alguma coisa escondida sem ser revelada. 0 indecifrável ligado à esfera da individualidade choca-se com o espetáculo, que é público, dado no espaço coletivo da rua, em que o narrador persegue o velho com uma compulsão similar à do perseguido, no desafio de lê-lo, explicá-lo logicamente, levado por sua imensa curiosidade. Mas é nessa perseguição que o próprio narrador se transforma em outro "homem da multidão", outro enigma entre enigmas, outro signo ilegível da cidade. Reciprocamente estranhos em sua perseguição circular, une-os em sua separação e alheamento, o 
fio secreto da solidão, marca do homem da multidão que "se recusa a estar só", único traço possível de ser lido desse enigma: "multidão, solidão: termos iguais e conversíveis" - diz Baudelaire em "Les foules", um dos Petits poèmes en prose, que, inspirado em Poe, constitui Le spleen de Paris. 0 homem da multidão reduplicado: ambos representam a realidade da própria cidade que não se deixa ler, mas que impõe uma leitura do ilegível.

Fixa-se, assim, a imagem da cidade moderna atada à figura do flâneur, que, em seus deslocamentos no espaço urbano, contracena com a multidão, o véu através do qual a cidade se revela. Experimenta, observa, especula, para engendrar uma possível leitura da cidade. Reedita a observação e a reflexão da matriz hoffmanniana. "O flanar não é simplesmente a um modo de experimentar a cidade. É um modo de experimentá-la. Olhando e contando o que se viu. Ao flanar, o sujeito urbano, privatizado, se aproxima da cidade como quem vê um objeto em exibição" (RAMOS, 2008, p. 148).

Nesta perspectiva, Julio Ramos propõe o conceito de "retórica do passeio", como a narrativização dos segmentos isolados do jornal e da cidade representada, frequentemente, em função de um sujeito que, ao caminhar pela cidade, traça o itinerário - um discurso - no discorrer do passeio" (RAMOS, 2008, p. 146). Segundo este teórico, é no passeio que o caminhante sai de seu interior para estabelecer relações com a cidade desordenada. Além de construir uma ordenação, portanto, uma leitura (significações), possibilitada também pela própria cidade que provêm meios para tal objetivo, o sujeito constrói e consolida identidades e classes (como se constata no conto de Poe, e de um ponto de vista fixo, também no de Hoffmann). Essa retórica do passeio assemelha-se ao que Michel de Certeau denomina "jogo dos passos ou enunciação pedestre", que molda espaços, tece lugares. "Sob esse ponto de vista, as motricidades dos pedestres formam um desses sistemas reais cuja existência faz efetivamente a cidade" (CERTEAU, 203, p. 176). Essa estratégia discursiva que associa visibilidade, espaço, abertura, é operação de vagar sem destino que procura captar e fixar o que o mapa urbano deseja transmitir e, além disso, reordenar o espaço urbano. 
Se esses dois contos com suas estratégias discursivas fixaram matrizes de representação da cidade moderna, talvez não fosse ocioso perguntar o que resta, hoje, dessas imagens. A rua como imagem do encontro, do diálogo, da philia que Anne Coquelin, em Essais de philosophie urbaine (1982, p. 8) vê como a função precípua da cidade, da cidade compartilhada, parece que foi corroída. Aconteceu o que Le Corbusier requeria: "precisamos acabar com a rua", lugar, antes de tudo, para o trânsito e o automóvel; ela virou a via expressa como imagem do progresso. $\mathrm{Ou}$ então virou o simulacro de ruas dos shopping-centers, dos consumidores disfarçados de flâneurs. "Narrar a cidade - assegura Canclini - é saber que já não é possível a experiência da ordem que o flâneur esperava estabelecer ao passear pela metrópole do início do século XX. Agora a cidade é como um videoclip: montagem efervescente de imagens descontínuas (...) saqueadas de todas as partes, em qualquer ordem" (1996, p. 131 e 135). Ou viraram zappeur, ou internautas que se entregam às infovias da Internet, ou aos fluxos das redes sociais. São outras estratégias de devassar o espaço público e o privado, num jogo sucessivo e infinito de janelas que se abrem: para um ver total, obsceno?, vale a pergunta.

Desta cidade, portanto, está eliminado o flâneur, esse personagem urbano, apontado por Allan Poe e fixado por Baudelaire, e que - repetimos mais uma vez tinha a rua como espaço de deambulação, e, com seu olhar inteligente mas desenraizado, contemplava, através da multidão, com seu ócio e sem pressa, o espetáculo cambiante do efêmero e do contigente da cidade transformada pela Revolução Industrial. Se a celebração da vitalidade urbana, de sua diversidade e plenitude, é um dos temas mais antigos da cultura moderna, cuja fantasia se cristalizou em torno da rua, que emergiu como símbolo fundamental da vida moderna, a cidade deste início de milênio vê praticamente esgarçada tal simbologia. A não ser que ela tente ser resgatada pelo viés nostálgico de um personagem que busca resistir e perverter esse esgarçamento e anda e vê o centro da cidade na esperança de reconstruir uma cidade compartilhada: refiro-me ao personagem Augusto, escritor diletante, do conto "A arte de andar nas ruas do Rio de Janeiro" (1992), de Rubem Fonseca. (ver GOMES, 2008, p. 160-178). 
Quanto à imagem da janela como ponto fixo de observação da cidade, perdeu sua amplitude. Dela se vê outras janelas, a exemplo do que se dá no filme Janela indiscreta (Rear Window, 1954, baseado no conto "It had to be murder", de Cornell Woolich, publicado em 1942), do genial Alfred Hitchcock, cuja intertextualidade remete nitidamente ao conto de Hoffmann. Ou ainda tem uma rentabilidade em textos como o romance policial Uma janela em Copacabana (2001), de Luiz-Alfredo Garcia-Roza, ou ainda no filme $O$ outro lado da rua (2004), de Marcos Berstein, que, intencionalmente ou não, dialoga com o filme de Hitchcock, o romance de Garcia-Roza e, por tabela, com o conto de Hoffmann.

Se a metáfora do teatro está adequada para a leitura da cidade nas representações discursivas midiáticas ou literárias que se desdobram dessas duas matrizes - as centradas na rua e na janela - , hoje, parece que se pode constatar o fim do espetáculo: "este não subsiste sem a separação entre o segredo da intimidade doméstica e o espaço público do consumo significativo; ou melhor, enquanto sobrevive tal distância, que é a da alienação, há o espetáculo - alguma ação em cena" - afirma Otília Arantes (1988, p. 268), retomando formulações de Baudrillard. Com a anulação de qualquer distanciamento, dá-se a imersão completa do sujeito no objeto. Há uma exposição plena, que cega, ao invés de seduzir. A obscenidade é o reino chapado da superfície.

Ou se quisermos retomar outra associação, poderíamos dizer que a janela de esquina do primo virou um programa de computador, são windows que se abrem sucessiva e simultaneamente, não para a praça do mercado, mas para a cidade virtual, formada por redes voláteis, a que podemos remeter a imagem que nos serviu de ponto de partida. Cada janela pode ser aquele ponto cego, que pode globalizar, numa ilusão de ótica, a totalidade. A janela se abre para outros mercados também voláteis. Janelas/windows que se abrem sobre a superfície chapada do mundo, numa época de globalização, em que todas as janelas são praticamente indiscretas e as ruas totalmente devassadas.

\section{Referências:}


ARANTES, O. "Arquitetura simulada". In: NOVAES, Adauto (org.). O olhar. São Paulo: Companhia das Letras, 1988.

AUGÉ, M.. Não-lugares: introdução a uma antropologia da sobremodernidade. Campinas: Papirus, 1992.

BAUDELAIRE, Ch. Oeuvres complètes. Paris: Robert Laffont, 1980.

BENJAMIN, W. Charles Baudelaire um lírico no auge do capitalismo. São Paulo: Brasiliense, 1989.

BERMAN, M. Tudo que é sólido desmancha no ar: a aventura da modernidade. São Paulo; Companhia das Letras, 1986.

CANCLINI, N. G. Consumidores \& cidadãos: conflitos culturais da globalização Rio de Janeiro: Ed. UFRJ, 1995.

Imaginarios urbanos. Buenos Aires: Editorial Universitaria de Buenos Aires, 1997.

CERTEAU, M. A invenção do cotidiano. V. 1, 9. ed. Pretópolis: Vozes, 2003.

CHARNEY, L. Num instante: o cinema e a filosofia as modernidade. In: CHARNEY, L. \& SCHWARTZ, V. K. (org.). 0 cinema e a invenção da vida moderna. 2 ed. São Paulo: Cosac \& Naify, 2004. p.317-334.

CHAUÍ, M. "Janela da alma, espelho do mundo". In: NOVAES, A. (org.). 0 olhar. São Paulo: Companhia das Letras, 1988.

COQUELIN, A. Essais de prilosophie urbaine. Paris: PUF, 1982.

DETHIER, J. "Por un musée imaginaire de la ville". In: e GUIHEUX, Alain (dir.). La ville: art et architecture en Europe - 1870-1993. Paris: Centre Georges Pompidou, 1994.

FONSECA, R. "A arte de andar nas ruas do Rio de Janeiro". In: Romance negro e outras histórias. São Paulo: Companhia das Letras, 1992.

GOMES, Renato Cordeiro. Todas as cidades, a cidade 2 ed.. Rio de Janeiro: Rocco, 2008.

HOFFMANN, E, T. A.janela de esquina do meu primo. Trad. Maria Aparecida Barbosa. São Paulo: CosacNaify, 2010.

POE, E. A. “O homem da multidão". In: Contos. Trad. José Paulo Paes. São Paulo: Cultix, 1986.

RABAN, J. Soft city. London: Harvill, 1988. 
RAMOS, J. Desencontros da modernidade na América latina: literatura e política no século 19. Belo Horizonte: Ed. UFMG, 2008.

STAROBINSKI, J. "Fenêtres (de Rousseau à Baudelaire)". In: L'idée de la ville. Actes du Colloque International de Lyon. Lyon: Editions de Chaml Vallon, 1984. p. 179-187. 